\title{
Intravesical Therapy for Non-Muscle-Invasive Bladder Cancer: What Is the Real Impact of Squamous Cell Carcinoma Variant on Oncological Outcomes?
}

\author{
Guglielmo Mantica ${ }^{1, *(\mathbb{D})}$, Francesco Chierigo ${ }^{1} \mathbb{D}$, Rafaela Malinaric ${ }^{1}$, Salvatore Smelzo ${ }^{2}$, Francesca Ambrosini ${ }^{1}$,

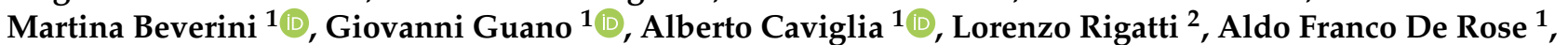 \\ Alessandro Tafuri ${ }^{3}$, Davide De Marchi ${ }^{2}$, Franco Gaboardi ${ }^{2}$, Nazareno Suardi ${ }^{1}$ and Carlo Terrone $^{1}$ \\ 1 Department of Urology, Policlinico San Martino Hospital, University of Genova, 16132 Genova, Italy; \\ francesco.chierigo@gmail.com (F.C.); rafaela.malinarc@gmail.com (R.M.); f.ambrosini1@gmail.com (F.A.); \\ martina.beverini@live.it (M.B.); giovanni.guano@gmail.com (G.G.); caviglialberto@gmail.com (A.C.); \\ aldofrancoderose@gmail.com (A.F.D.R.); suardi.nazareno@gmail.com (N.S.); \\ carlo.terrone@med.uniupo.it (C.T.) \\ 2 Department of Urology, San Raffaele Turro Hospital, 20127 Milan, Italy; salvatore.smelzo@hsr.it (S.S.); \\ rigatti.lorenzo@hsr.it (L.R.); demarchidavide82@gmail.com (D.D.M.); gaboardi.franco@hsr.it (F.G.) \\ 3 Department of Urology, Vito Fazzi Hospital, 73110 Lecce, Italy; aletaf@hotmail.it \\ * Correspondence: guglielmo.mantica@gmail.com; Tel.: +39-010-555-3935
}

Citation: Mantica, G.; Chierigo, F.; Malinaric, R.; Smelzo, S.; Ambrosini, F.; Beverini, M.; Guano, G.; Caviglia, A.; Rigatti, L.; De Rose, A.F.; et al. Intravesical Therapy for Non-Muscle-Invasive Bladder Cancer: What Is the Real Impact of Squamous Cell Carcinoma Variant on Oncological Outcomes?. Medicina 2022, 58, 90. https://doi.org/ $10.3390 /$ medicina58010090

Academic Editor: Giuseppe Lucarelli

Received: 27 November 2021

Accepted: 1 January 2022

Published: 7 January 2022

Publisher's Note: MDPI stays neutral with regard to jurisdictional claims in published maps and institutional affiliations.

Copyright: (C) 2022 by the authors. Licensee MDPI, Basel, Switzerland. This article is an open access article distributed under the terms and conditions of the Creative Commons Attribution (CC BY) license (https:// creativecommons.org/licenses/by/ $4.0 /)$.

\begin{abstract}
Background and Objectives: To evaluate the oncological impact of squamous cell carcinoma (SCC) variant in patients submitted to intravesical therapy for non-muscle-invasive bladder cancer (NMIBC). Materials and Methods: Between January 2015 and January 2020, patients with conventional urothelial NMIBC (TCC) or urothelial NMIBC with SCC variant (TCC + SCC) and submitted to adjuvant intravesical therapies were collected. Kaplan-Meier analyses targeted disease recurrence and progression. Uni- and multivariable Cox regression analyses were used to test the role of SCC on disease recurrence and/or progression. Results: A total of 32 patients out of 353 had SCC at diagnosis. Recurrence was observed in $42 \%$ of TCC and $44 \%$ of TCC + SCC patients $(p=0.88)$, while progression was observed in $12 \%$ of both TCC and TCC + SCC patients $(p=0.78)$. At multivariable Cox regression analyses, the presence of SCC variant was not associated with higher rates of neither recurrence $(p=0.663)$ nor progression $(p=0.582)$. Conclusions: We presented data from the largest series on patients with TCC and concomitant SCC histological variant managed with intravesical therapy (BCG or MMC). No significant differences were found in term of recurrence and progression between TCC and TCC + SCC. Despite the limited sample size, this study paves the way for a possible implementation of the use of intravesical BCG and MMC in NMIBC with histological variants.
\end{abstract}

Keywords: squamous cell carcinoma; urinary bladder neoplasms; regression analysis; neoplasm recurrence; adjuvants

\section{Introduction}

Bladder cancer (BCa) is one of the most common malignancies, and it counts for about 165,000 deaths / year worldwide [1-3]. Overall, $75 \%$ of newly diagnosed BCas are non-muscle-invasive (NMIBC), which is a disease burdened by recurrence in more than $60 \%$ of cases and progression in more than $10 \%[4,5]$. The most predominant histological phenotype is the conventional urothelial carcinoma/Transitional Cell Carcinoma (TCC), which constitutes about $80 \%$ of bladder cancer. Histological variants (HVs) [6,7] are present in up to $20 \%$ of patients, and the squamous cell carcinoma (SCC) variant in roughly $10 \%$ of patients [8]. The role of HVs in NMIBC has become of great interest over the last decade. The presence of HVs is generally associated with a worse prognosis and a high risk of under-staging at the transurethral resection of the bladder tumor (TURBT) because of the small sample sizes and tumor heterogeneity. Urothelial variants present with histological 
features in common with conventional urothelial carcinoma and also display foci of specific different histomorphological phenotypes. Highly aggressive HVs are sarcomatoid carcinoma, plasmacytoid carcinoma, and micropapillary carcinoma. Furthermore, squamous and glandular differentiation show aggressive behavior. Nested, small tubular, microcystic, and inverted papilloma-like variants have been grouped under the heading of deceptively benign carcinomas because of their bland appearance and low-grade feature. Early radical cystectomy (RC) is often proposed in the majority of cases of high-grade (HG) NMIBC, although whether or not early radical cystectomy should be recommended has not been established yet. Squamous or glandular differentiation, deceptively benign carcinomas, and lymphoepithelioma such as carcinoma can initially be managed with restaging TURB followed by intravesical BCG (Bacillus Calmette-Guérin). However, any other urothelial or nonurothelial variants should be promptly considered for early radical cystectomy [4,9-11].

However, there is still little evidence on the impact of these variants on prognosis, recurrence, and management of $\mathrm{BCa}[9]$.

Currently, literature is scant of studies evaluating the efficacy and outcomes of adjuvant intravesical therapy in patients with HV [9].

Most of the very few published reports are focused on glandular or squamous variants, based on a series of 6-30 cases, and comparing patients managed with intravesical Bacillus Calmette-Guerin (BCG) to those submitted to RC [11-15].

These studies showed that both intravesical BCG and RC lead to a survival gain in high-risk patients diagnosed with NMIBC with squamous or glandular histologic variants and that RC was not mandatory for all of them [12,13].

A recent study by Gofrit et al. [16] compared the oncological outcomes of 41 patients with high-grade (HG) NMIBC + HV (any type) managed with intravesical BCG to those with conventional HG NMIBC. A total of 14 patients were diagnosed with micropapillary differentiation, 13 patients with squamous differentiation, 9 patients with glandular differentiation, and 7 patients with nested variants. The 2- and 5-year survival rates of the four variants were quite similar to each other. Patients with the glandular variant had a tendency toward a better prognosis, while patients with the micropapillary and squamous variants exhibited a worse prognosis. As compared with conventional urothelial carcinoma, patients with HV have a significantly worse prognosis, including 5-year, recurrence-free survival; 5-year progression-free survival; and overall survival. However, the series accounted for only 13 patients with squamous differentiation [16].

Within this paucity of data, the aim of this study is to analyze the efficacy of adjuvant intravesical chemotherapy (BCG or Mitomycin C (MMC)) in patients with NMIBC and SCC variant in a larger series.

\section{Materials and Methods}

\subsection{Study Design and Patient Population}

Between January 2015 and January 2020, data of all patients affected by NMIBC and submitted to adjuvant intravesical therapies in two tertiary care referral centers were prospectively collected in our multi-institutional databases and retrospectively analyzed. Anamnestic information such as age and gender and clinicopathological data (histology at TURBT, American Joint Committee on Cancer (TNM) staging) available at the time of the adjuvant intravesical therapy were recorded. We included patients with TURBT pathological reports showing a conventional urothelial NMIBC (TCC) or urothelial NMIBC with any percentage of associated SCC variant (TCC + SCC), alone or in combination with Carcinoma in situ (CIS), with intermediate or high-risk of recurrence and progression [4].

No blue-light cystoscopy and narrow-band imaging as diagnostic tools were used.

All patients were treated with adjuvant intravesical therapy (either BCG or MMC) according to the current European Association of Urology (EAU) guidelines [17]. Only patients submitted to TURBT at our institutions were included in the study. Patients who underwent a single early postoperative instillation of chemotherapy or those who did 
not complete the induction were excluded. Patients with incomplete information were excluded from the study.

All the TURBT specimens were analyzed by uropathologists of the same pathology department. Diagnosis of urothelial bladder carcinoma with rare SCC variant differentiation was based on the identification of specific histological features according to the World Health Organization classification in use at the time of diagnosis. SCC can be described as an epithelial neoplasm exclusively displaying histological features such as squamous pearls, intercellular bridges, or keratinization [18]. Molecular squamous markers used were CK5/6, p63, p40, CK14, and desmoglein 3. Pathological staging was established according to the TNM system [19].

\subsection{Adjuvant Intravesical Therapy and Follow-Up}

The adjuvant intravesical MMC was administered according to the Southwest Oncology Group (SWOG) regimen: induction with a weekly injection per 6 weeks + maintenance with a monthly injection up to 12 months. Similarly, the BCG scheme included a weekly injection up to 6 weeks and a maintenance every 3-6 months up to 36 months [17].

Patients were followed-up with cystoscopy, ultrasound, and urine cytology according to EAU guidelines recommendations [4]. The exact date of disease recurrence and/or progression was recorded. We evaluated the differences in terms of age, stage, grade, and risk factors and compared such variables between TCC and TCC + SCC patients. Moreover, the response to intravesical therapy (BCG or MMC) was evaluated in both TCC and TCC + SCC patients in terms of disease recurrence and/or progression. Disease progression was defined as any upgrade to a higher pathological T (pT) stage. We considered the followup time starting from the histological diagnosis.

\subsection{Statistical Analysis}

Data were entered into a Microsoft Excel (version 14.0) (Microsoft Corporation, Redmond, WA, USA)database and transferred to SPSS v.24.0 for Windows (IBM Corp., Armonk, NY, USA). Continuous and non-normally distributed variables are presented as medians with interquartile ranges (IQRs). For the comparison between demographic and pathological data Mann-Whitney and Chi-squared tests were used for continuous and categorical variables, respectively. Kaplan-Meier analyses targeted disease recurrence and progression according to the presence of SCC as well as according to the different intravesical drugs. Finally, uni- and multivariable Cox regression analyses were used to test the role of SCC on disease recurrence and/or progression.

\section{Results}

Overall, a total of 353 patients were evaluated. Of these, 32 (9.1\%) had SCC at diagnosis. No significant differences in terms of mean age, smoking, pT1 stage, high grade, concomitant carcinoma in situ, dimensions, and single vs. multiple lesions were found between TCC + SCC and TCC patients, respectively (Table 1$)$. Three patients $(0.9 \%)$ were pT2 at the TURBT and underwent intravesical therapy, having refused RC. Intravesical therapy with MMC was administered in 15 (47\%) TCC + SCC vs. 163 (51\%) TCC patients, respectively. Intravesical therapy with BCG was administered in $17(53 \%)$ TCC + SCC vs. 142 (44\%) TCC patients, respectively. Furthermore, 16 TCC patients underwent epirubicin (Table 1).

Median follow-up was 36 (IQR: 18-50) months. Oncological outcomes are shown in Tables $1-3$ and Figures $1-4$. Recurrence was observed in $42 \%$ of TCC and $44 \%$ of TCC + SCC patients $(p=0.88)$, while progression was observed in $12 \%$ of both TCC and TCC + SCC patients $(p=0.78)$. Patients treated with MMC showed a 1- and 3- year recurrence-free survival (RFS) of $74 \%$ and $51 \%$ for TCC and $60 \%$ and $43 \%$ in TCC + SCC, respectively. Patients treated with BCG showed a 1- and 3- year RFS of $62 \%$ and $42 \%$ for TCC and $71 \%$ and $59 \%$ for TCC + SCC, respectively. 
Table 1. Clinical and pathological characteristics at diagnosis and recurrence.

\begin{tabular}{|c|c|c|c|c|}
\hline Characteristic & Overall, $n=353$ & TCC, $n=321$ & $\mathrm{TCC}+\mathrm{SCC}, n=32$ & $p$-Value \\
\hline Age & $72(65,78)$ & $72(65,78)$ & $72(66,79)$ & 0.72 \\
\hline Smoking, $n(\%)$ & & & & 0.10 \\
\hline No & $42(12 \%)$ & $40(12 \%)$ & $2(6.2 \%)$ & \\
\hline Yes & $196(56 \%)$ & $182(57 \%)$ & $14(44 \%)$ & \\
\hline Ex & $115(33 \%)$ & $99(31 \%)$ & $16(50 \%)$ & \\
\hline Single vs. Multiple, $n(\%)$ & & & & 0.60 \\
\hline Single & $203(58 \%)$ & $186(58 \%)$ & $17(53 \%)$ & \\
\hline Multiple & $150(42 \%)$ & $135(42 \%)$ & $15(47 \%)$ & \\
\hline Dimensions, $n(\%)$ & & & & 0.40 \\
\hline$<3 \mathrm{~cm}$ & $196(56 \%)$ & $176(55 \%)$ & $20(62 \%)$ & \\
\hline$\geq 3 \mathrm{~cm}$ & $157(44 \%)$ & $145(45 \%)$ & $12(38 \%)$ & \\
\hline Histology, $n(\%)$ & & & & 0.57 \\
\hline pTa & $186(53 \%)$ & $172(54 \%)$ & $14(44 \%)$ & \\
\hline pT1 & $144(41 \%)$ & $127(40 \%)$ & $17(53 \%)$ & \\
\hline pT2 & $3(0.8 \%)$ & $3(0.9 \%)$ & $0(0 \%)$ & \\
\hline Cis & $19(5.4 \%)$ & $18(5.6 \%)$ & $1(3.1 \%)$ & \\
\hline $\mathrm{Tx}$ & $1(0.3 \%)$ & $1(0.3 \%)$ & $0(0 \%)$ & \\
\hline Grading, $n(\%)$ & & & & 0.40 \\
\hline Low & $100(28 \%)$ & $93(29 \%)$ & $7(22 \%)$ & \\
\hline High & $253(72 \%)$ & $228(71 \%)$ & $25(78 \%)$ & \\
\hline Concomitant Cis & $10(2.8 \%)$ & $9(2.8 \%)$ & $1(3.1 \%)$ & $>0.99$ \\
\hline Therapy, $n(\%)$ & & & & 0.65 \\
\hline MMC & $178(50 \%)$ & $163(51 \%)$ & $15(47 \%)$ & \\
\hline BCG & $159(45 \%)$ & $142(44 \%)$ & $17(53 \%)$ & \\
\hline Epirubicin & $16(4.5 \%)$ & $16(4.9 \%)$ & $0(0 \%)$ & \\
\hline $\begin{array}{c}\text { Histology at Recurrence, } \\
n(\%)\end{array}$ & & & & 0.066 \\
\hline $\mathrm{Ta}$ & $98(64 \%)$ & $91(65 \%)$ & $7(50 \%)$ & \\
\hline $\mathrm{T} 1$ & $33(22 \%)$ & $29(21 \%)$ & $4(29 \%)$ & \\
\hline $\mathrm{T} 2$ & $4(2.6 \%)$ & $2(1.4 \%)$ & $2(14 \%)$ & \\
\hline Cis & $18(12 \%)$ & $17(12 \%)$ & $1(7.1 \%)$ & \\
\hline $\mathrm{Tx}$ & $0(0 \%)$ & $0(0 \%)$ & $0(0 \%)$ & \\
\hline $\begin{array}{c}\text { Grading at Recurrence, } \\
n(\%)\end{array}$ & & & & 0.29 \\
\hline Low & $64(42 \%)$ & $60(43 \%)$ & $4(29 \%)$ & \\
\hline High & $89(58 \%)$ & $79(57 \%)$ & $10(71 \%)$ & \\
\hline $\begin{array}{c}\text { Concomitant } \mathrm{Cis} \text { at } \\
\text { Recurrence }\end{array}$ & $5(3.3 \%)$ & $4(2.9 \%)$ & $1(7.1 \%)$ & 0.39 \\
\hline Time To Recurrence & $35(15,58)$ & $33(16,57)$ & $40(13,78)$ & 0.44 \\
\hline Recurrence, $n(\%)$ & $150(42 \%)$ & $136(42 \%)$ & $14(44 \%)$ & 0.88 \\
\hline Progression, $n(\%)$ & $42(12 \%)$ & $38(12 \%)$ & $4(12 \%)$ & 0.78 \\
\hline Time To Progression & $36(16,58)$ & $36(16,57)$ & $40(13,78)$ & 0.51 \\
\hline
\end{tabular}

$\overline{\mathrm{CI}}=$ confidence interval. TCC $=$ Transitional Cell Carcinoma. SCC = squamous cell carcinoma. Cis = carcinoma in situ. BCG = Bacillus Calmette-Guerin. MMC = Mitomycin C. 
Table 2. Multivariable Cox regression analysis predicting recurrence.

\begin{tabular}{ccccc}
\hline & \multicolumn{2}{c}{ Univariable } & \multicolumn{2}{c}{ Multivariable } \\
\hline & HR $(\mathbf{9 5} \%$ CI $)$ & $p$-Value & HR (95\% CI) & $p$-Value \\
\hline Age & $1.00(0.99,1.01)$ & 0.896 & $1.00(0.99,1.01)$ & 0.947 \\
\hline Smoking (No as Ref) & & 0.592 & & 0.643 \\
\hline Yes & $0.96(0.58,1.59)$ & 0.872 & $0.93(0.55,1.58)$ & 0.792 \\
\hline Ex-smoker & $1.16(0.68,1.97)$ & 0.591 & $1.11(0.63,1.96)$ & 0.710 \\
\hline Single vs. Multi (Single as Ref) & $1.07(0.76,1.49)$ & 0.702 & $1.07(0.76,1.53)$ & 0.691 \\
\hline Dimension (<3 cm as Ref) & $0.99(0.71,1.38)$ & 0.958 & $1.01(0.71,1.44)$ & 0.948 \\
\hline TCC vs. TCC + SCC & $1.03(0.59,1.79)$ & 0.915 & $0.88(0.50,1.56)$ & 0.663 \\
\hline Histology (Ta as Ref) & & 0.041 & & 0.033 \\
\hline T1 & $1.59(0.64,3.95)$ & 0.315 & $1.30(0.85,2.00)$ & 0.229 \\
\hline T2 & $1.76(0.71,4.41)$ & 0.224 & $5.20(1.53,17.69)$ & 0.008 \\
\hline Cis & $7.48(1.77,31.60)$ & 0.006 & $0.73(0.28,1.92)$ & 0.528 \\
\hline Grading (Low as Ref) & $0.79(0.55,1.12)$ & 0.183 & $0.52(0.31,0.88)$ & 0.015 \\
\hline Concomitant Cis (No as Ref) & $1.22(0.52,2.87)$ & 0.653 & $1.20(0.51,2.87)$ & 0.674 \\
\hline BCG vs. MMC (MMC as Ref) & $1.17(0.84,1.64)$ & 0.362 & $1.47(0.93,2.35)$ & 0.103 \\
\hline
\end{tabular}

$\overline{\mathrm{CI}}=$ confidence interval. TCC $=$ Transitional Cell Carcinoma. SCC $=$ squamous cell carcinoma. Cis $=$ carcinoma in situ. BCG = Bacillus Calmette-Guerin. $\mathrm{MMC}=$ Mitomycin C.

Table 3. Multivariable Cox regression analysis predicting progression.

\begin{tabular}{ccccc}
\hline & \multicolumn{2}{c}{ Univariable } & \multicolumn{2}{c}{ Multivariable } \\
\hline & HR $(\mathbf{9 5} \% \mathbf{C I})$ & $p$-Value & HR $(\mathbf{9 5} \% \mathbf{C I})$ & $p$-Value \\
\hline Age & $1.01(0.99,1.04)$ & 0.369 & $1.01(0.99,1.04)$ & 0.303 \\
\hline Smoking (No as Ref) & & 0.118 & & 0.090 \\
\hline Yes & $1.21(0.41,3.58)$ & 0.728 & $1.20(0.39,3.64)$ & 0.753 \\
\hline Ex-smoker & $2.26(0.75,6.83)$ & 0.147 & $2.40(0.76,7.58)$ & 0.135 \\
\hline Single vs. Multi (Single as Ref) & $0.94(0.50,1.79)$ & 0.856 & $0.80(0.40,1.57)$ & 0.509 \\
\hline Dimension (<3 cm as Ref) & $1.06(0.57,1.95)$ & 0.865 & $1.03(0.54,1.97)$ & 0.936 \\
\hline TCC vs. TCC + SCC & $1.06(0.38,3.01)$ & 0.907 & $0.74(0.25,2.17)$ & 0.582 \\
\hline Histology (Ta as Ref) & & 0.072 & & 0.298 \\
\hline T1 & $1.88(0.97,3.65)$ & 0.061 & $1.67(0.76,3.68)$ & 0.203 \\
\hline T2 & $9.42(1.21,73.23)$ & 0.032 & $6.48(0.75,55.63)$ & 0.089 \\
\hline Cis & $1.89(0.55,6.55)$ & 0.316 & $1.82(0.46,7.10)$ & 0.392 \\
\hline Grading (Low as Ref) & $0.55(0.24,1.26)$ & 0.158 & $0.88(0.29,2.66)$ & 0.814 \\
\hline BCG vs. MMC (MMC as Ref) & $2.08(1.09,3.97)$ & 0.026 & $1.81(0.79,4.15)$ & 0.159 \\
\hline
\end{tabular}

$\overline{\mathrm{CI}}=$ confidence interval. TCC $=$ Transitional Cell Carcinoma. SCC $=$ squamous cell carcinoma. Cis = carcinoma in situ. BCG = Bacillus Calmette-Guerin. $\mathrm{MMC}=$ Mitomycin C.

At multivariable Cox regression analyses, after adjusting for age, $\mathrm{pT}$ stage, and grade at diagnosis as well as the type of intravesical therapy, the presence of SCC variant at TURBT was associated with higher rates of neither recurrence $(p=0.663)$ nor progression $(p=0.582)$ (Tables 2 and 3). 


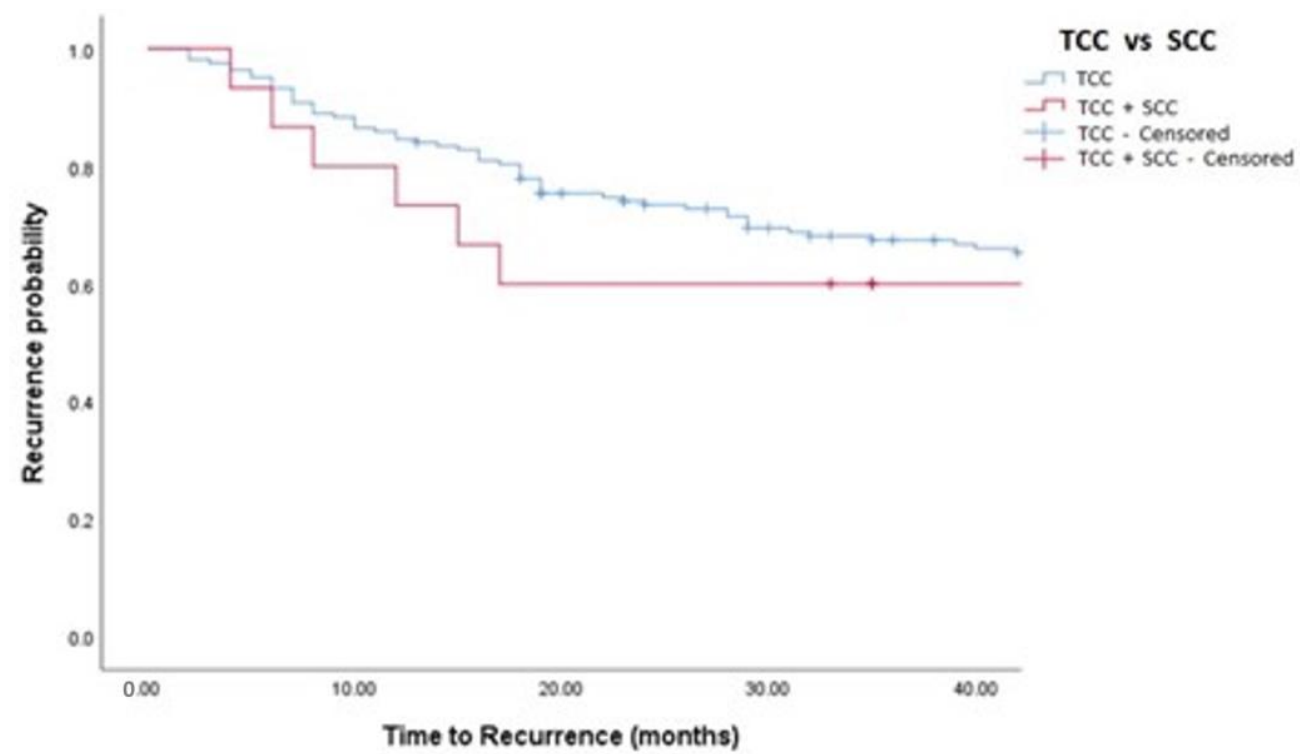

Figure 1. Kaplan-Meier analysis showing estimates of disease recurrence in TCC and TCC + SCC patients treated with MMC ( $\log$-rank $p=0.448)$. TCC $=$ Conventional Urothelial non-muscle-invasive bladder cancer. SCC $=$ Squamous Cell Carcinoma.

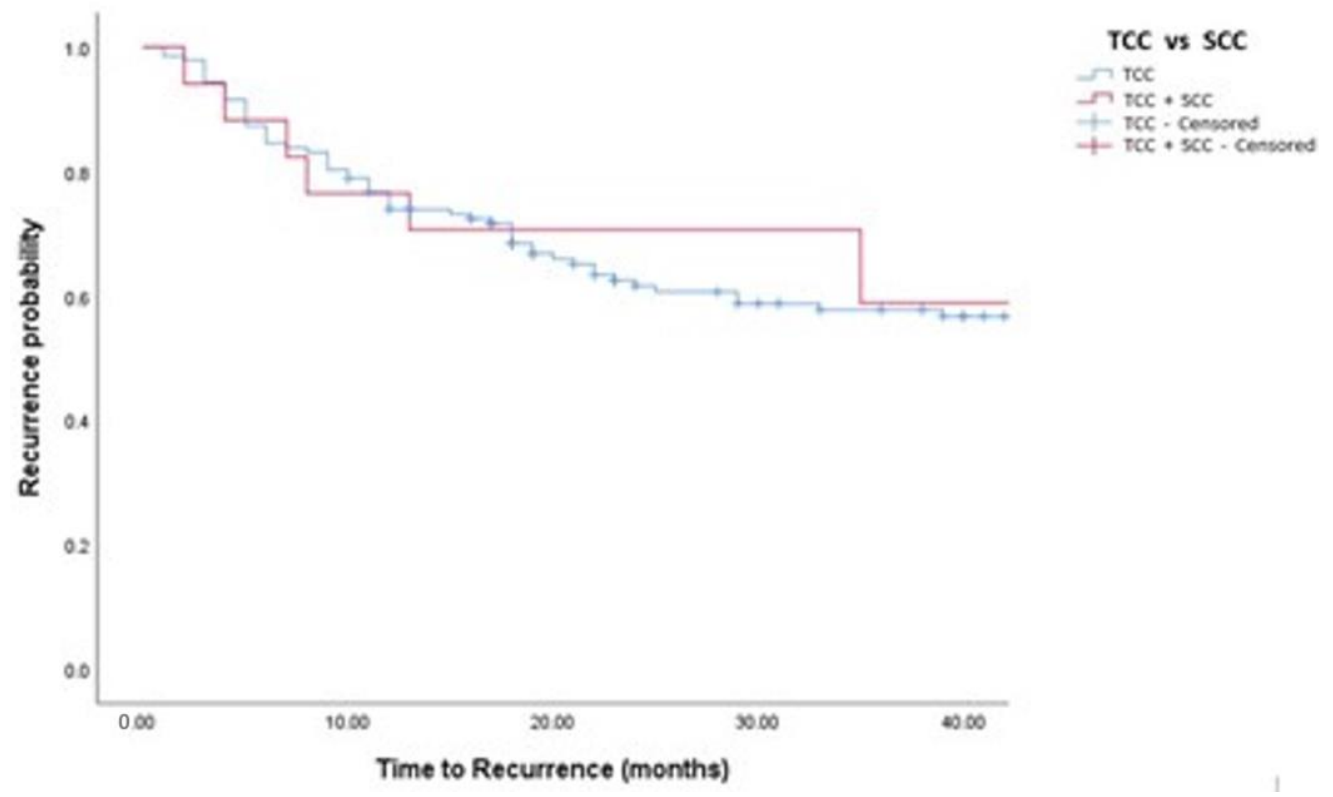

Figure 2. Kaplan-Meier analysis showing estimates of disease recurrence in in TCC and TCC + SCC patients treated with BCG $(\log$-rank $p=0.532)$. 


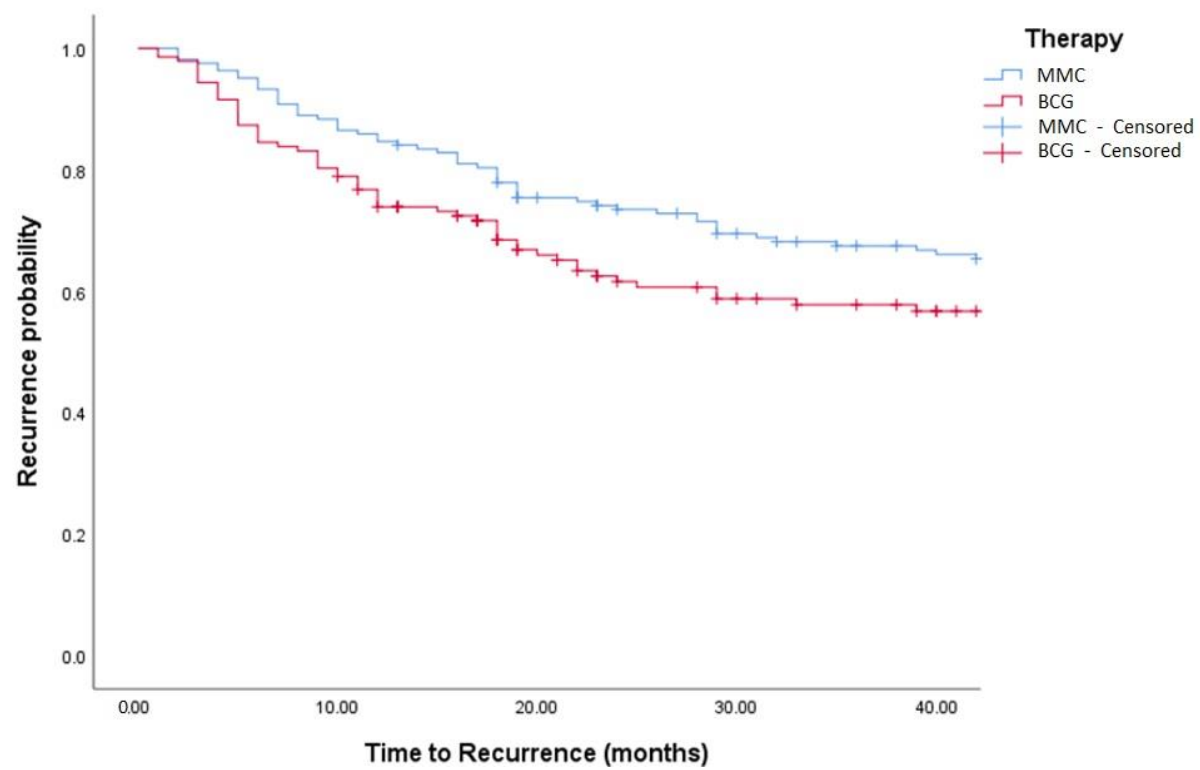

Figure 3. Kaplan-Meier in BCG vs. MMC in TCC patients (log-rank, $p=0.271$ ). BCG = Bacillus Calmette Guerin. MCC = Mitomycin C.

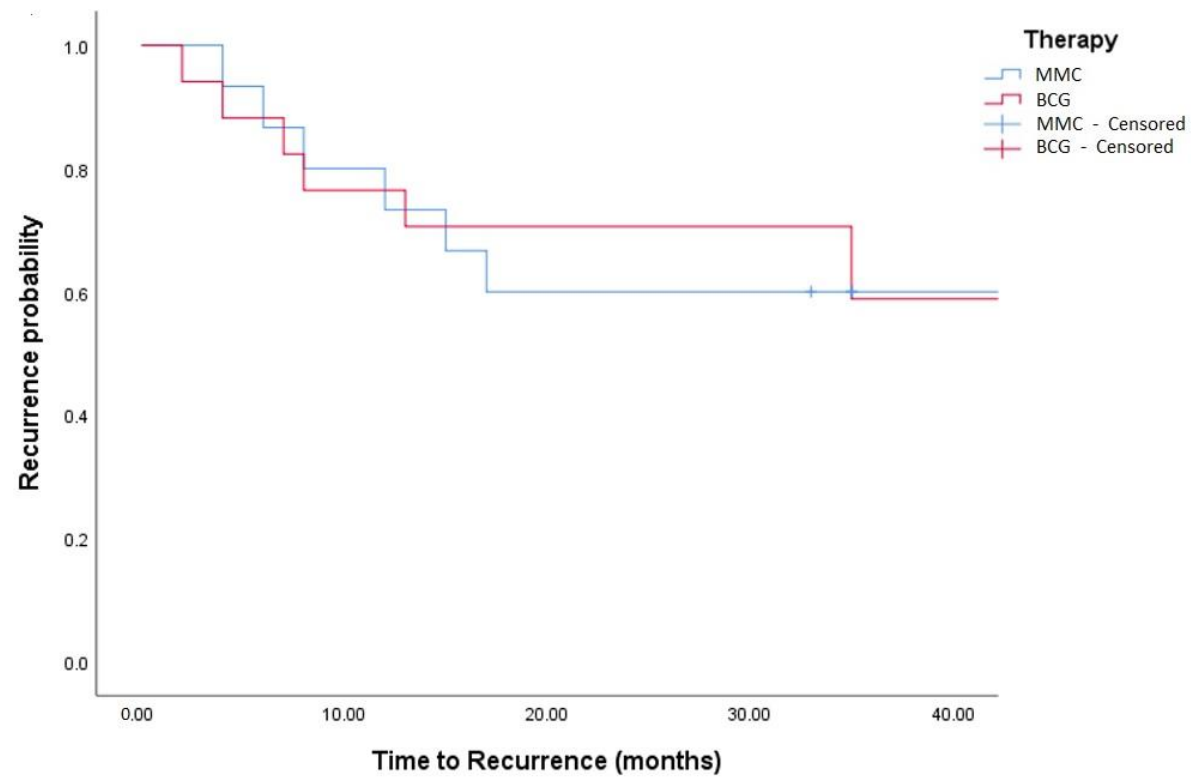

Figure 4. Kaplan-Meier in TCC + SCC patients (log-rank, $p=0.759)$.

\section{Discussion}

BCa HV, and therefore also SCC, are usually considered to have a poor prognosis, and patients are generally submitted to aggressive treatments, such as early cystectomy $[9,20]$. Currently, literature is scant of studies evaluating the efficacy and outcomes of adjuvant intravesical therapy in patients with HV. Most of these few studies, mainly based on less than a dozen of patients with glandular or squamous variants, showed that both intravesical BCG and RC lead to a survival gain in high-risk patients diagnosed with NMIBC bladder cancer with squamous or glandular histologic variants and that RC is not mandatory for every patient $[12,13]$.

Our study represents, currently, the largest series on patients with SCC variant managed with intravesical therapy. At a median follow-up of 36 months, no significant differences were found in terms of recurrence and progression between TCC and TCC + SCC patients. 
Patients treated with MMC showed a 1- and 3- year RFS of 74\% and $51 \%$ for TCC and $60 \%$ and $43 \%$ in TCC + SCC, respectively. Patients treated with BCG showed a 1- and 3- year RFS of $62 \%$ and $42 \%$ for TCC and $71 \%$ and $59 \%$ for TCC + SCC, respectively.

At multivariable Cox regression analyses, after adjusting for age, $\mathrm{pT}$ stage, and grade at diagnosis as well as the type of intravesical therapy, the presence of SCC variant at TUR was associated with higher rates of neither recurrence $(p=0.663)$ nor progression $(p=0.582)$.

Anecdotally, looking at other fields, in particular regarding squamous cell carcinoma, irrigation and topical use of MMC and BCG are successfully reported in selected cases of squamous cell carcinoma of the head and neck or lung [21-23]. Similarly, BCG is widely used in the veterinary field for the management of ocular squamous cell carcinoma in bovines [24,25].

This study has several limitations. Firstly, the possible biases of a multicentric study, with different operators administering the intravesical therapy and following the patients. Secondly, although the data were collected prospectively, there was no randomization of patients. Furthermore, the control group over the same time period appears much larger than the study group. Third, there may have been a selection bias of patients undergoing intravesical instillation rather than early cystectomy. Fourth, the percentage of SCC variant on histology is heterogeneous, and it could impact the results. However, given the limited sample size and the short follow-up, it is impossible to statistically evaluate the impact with these data.

Almost no data are available in literature on intravesical management of TCC with HV, mainly due to the aggressiveness of the neoplasm for which urologists tend to recommend more aggressive management such as early cystectomy. Despite the numerous concerns, these preliminary data could lead at least to considering intravesical therapy in patients with TCC associated with some variants, in particular SCC.

\section{Conclusions}

We presented data from the largest series on patients with TCC and concomitant SCC histological variant managed with intravesical therapy (BCG or MMC). At a median follow-up of 36 months, no significant differences were found in terms of recurrence and progression between TCC and TCC + SCC. Furthermore, the presence of the SCC variant at TURBT was associated with neither higher recurrence nor progression rates. Despite the limited sample size and numerous biases, this study paves the way for a possible implementation of the use of intravesical BCG and MMC in NMIBC with HV. Further, larger multicentric and randomized trials are needed to confirm these preliminary data.

Author Contributions: G.M. conceived and designed the study and wrote the paper, F.C. performed the analysis, R.M. collected the data, S.S. collected the data, F.A. collected the data, M.B. collected the data, G.G. collected the data, A.C. collected the data, L.R. collected the data, A.F.D.R. supervised the research, A.T. supervised the manuscript, D.D.M. collected the data, F.G. supervised the research, N.S. edited the final manuscript and supervised the research, and C.T. supervised the research. All authors have read and agreed to the published version of the manuscript.

Funding: This research received no external funding.

Institutional Review Board Statement: The study was conducted according to the guidelines of the Declaration of Helsinki and approved by the Institutional Review Board and an informed consent was obtained from all the participants (CONSAZHQA_0001).

Informed Consent Statement: Informed consent was obtained from all subjects involved in the study. In our institution, the patients at the hospital admission sign an informed consent to allow the collection and analysis of data.

Data Availability Statement: Data are available at the Institutional Database.

Acknowledgments: The authors acknowledge the uropathologists of our institutes that actively participated in the development of the research. 
Conflicts of Interest: The authors declare no conflict of interest.

\section{References}

1. Sung, H.; Ferlay, J.; Siegel, R.L.; Laversanne, M.; Soerjomataram, I.; Jemal, A.; Bray, F. Global Cancer Statistics 2020: GLOBOCAN Estimates of Incidence and Mortality Worldwide for 36 Cancers in 185 Countries. CA Cancer J. Clin. 2021, 71, 209-249. [CrossRef]

2. Abdou Hassan, W.; Shalaby, E.; Abo-Hashesh, M.; Ibrahim Ali, R. Evaluation of the Expression of HER2 and c-KIT Proteins as Prognostic Markers in Superficial Bladder Urothelial Carcinoma. Res. Rep. Urol. 2021, 13, 197-206. [CrossRef]

3. Peyrottes, A.; Ouzaid, I.; Califano, G.; Hermieu, J.-F.; Xylinas, E. Neoadjuvant Immunotherapy for Muscle-Invasive Bladder Cancer. Medicina 2021, 57, 769. [CrossRef]

4. Babjuk, M.; Burger, M.; Compérat, E.; Gontero, P.; Liedberg, F.; Masson-Lecomte, A.; Mostafid, A.H.; Palou, J.; van Rhijn, B.W.G.; Rouprêt, M.; et al. EAU Guidelines 2021 on Non-Muscle-Invasive Bladder Cancer. Available online: www.uroweb.org (accessed on 15 August 2021).

5. Sawazaki, H.; Arai, Y.; Ito, Y.; Sato, K.; Tsuda, H.; Yamaga, T.; Sakurai, H. Expression of L-Type Amino Acid Transporter 1 is a Predictive Biomarker of Intravesical Recurrence in Patients with Non-Muscle Invasive Bladder Cancer. Res. Rep. Urol. 2021, 13, 603-611. [CrossRef]

6. Hansel, D.E.; Amin, M.B.; Comperat, E.; Cote, R.J.; Knüchel, R.; Montironi, R.; Reuter, V.E.; Soloway, M.S.; Umar, S.A.; Van der Kwast, T. A Contemporary Update on Pathology Standards for Bladder Cancer: Transurethral Resection and Radical Cystectomy Specimens. Eur. Urol. 2012, 63, 321-332. [CrossRef]

7. Mantica, G.; Tappero, S.; Parodi, S.; Piol, N.; Spina, B.; Malinaric, R.; Balzarini, F.; Borghesi, M.; Van Der Merwe, A.; Suardi, N.; et al. Bladder cancer histological variants: Which parameters could predict the concordance between transurethral resection of bladder tumor and radical cystectomy specimens? Cent. Eur. J. Urol. 2021, 74, 355-361.

8. Mantica, G.; Simonato, A.; Du Plessis, D.E.; Maffezzini, M.; De Rose, A.F.; van der Merwe, A.; Terrone, C. The pathologist's role in the detection of rare variants of bladder cancer and analysis of the impact on incidence and type detection. Minerva Urol. Nefrol. 2018, 70, 594-597. [CrossRef]

9. Baumeister, P.; Zamboni, S.; Mattei, A.; Antonelli, A.; Simeone, C.; Mordasini, L.; DiBona, C.; Moschini, M. Histological variants in non-muscle invasive bladder cancer. Transl. Androl. Urol. 2019, 8, 34-38. [CrossRef]

10. Goutas, D.; Tzortzis, A.; Gakiopoulou, H.; Vlachodimitropoulos, D.; Giannopoulou, I.; Lazaris, A.C. Contemporary Molecular Classification of Urinary Bladder Cancer. In Vivo 2021, 35, 75-80. [CrossRef]

11. Seisen, T.; Compérat, E.; Léon, P.; Roupret, M. Impact of histological variants on the outcomes of nonmuscle invasive bladder cancer after transurethral resection. Curr. Opin. Urol. 2014, 24, 524-531. [CrossRef]

12. Suh, J.; Moon, K.C.; Jung, J.H.; Lee, J.; Song, W.H.; Kang, Y.J.; Jeong, C.W.; Kwak, C.; Kim, H.H.; Ku, J.H. BCG instillation versus radical cystectomy for high-risk NMIBC with squamous/glandular histologic variants. Sci. Rep. 2019, 9, 15268. [CrossRef]

13. Shapur, N.K.; Katz, R.; Pode, D.; Shapiro, A.; Yutkin, V.; Pizov, G.; Appelbaum, L.; Zorn, K.C.; Duvdevani, M.; Landau, E.H.; et al. Is radical cystectomy mandatory in every patient with variant histology of bladder cancer. Rare Tumors 2011, 3, 67-70. [CrossRef] [PubMed]

14. Miller, J.S.; Epstein, J.I. Noninvasive urothelial carcinoma of the bladder with glandular differentiation: Report of 24 cases. Am. J. Surg. Pathol. 2009, 33, 1241-1248. [CrossRef]

15. Yorozuya, W.; Nishiyama, N.; Shindo, T.; Kyoda, Y.; Itoh, N.; Sugita, S.; Hasegawa, T.; Masumori, N. Bacillus Calmette-Guérin may have clinical benefit for glandular or squamous differentiation in non-muscle invasive bladder cancer patients: Retrospective multicenter study. Jpn. J. Clin. Oncol. 2018, 48, 661-666. [CrossRef]

16. Gofrit, O.N.; Yutkin, V.; Shapiro, A.; Pizov, G.; Zorn, K.C.; Hidas, G.; Gielchinsky, I.; Duvdevani, M.; Landau, E.H.; Pode, D. The Response of Variant Histology Bladder Cancer to Intravesical Immunotherapy Compared to Conventional Cancer. Front. Oncol. 2016, 6, 43. [CrossRef]

17. Lamm, D.L.; Blumenstein, B.A.; Crissman, J.D.; Montie, J.E.; Gottesman, J.E.; Lowe, B.A.; Sarosdy, M.F.; Bohl, R.D.; Grossman, H.B.; Beck, T.M.; et al. Maintenance Bacillus Calmette-Guerin immunotherapy for recurrent TA, T1 and carcinoma in situ transitional cell carcinoma of the bladder: A randomized Southwest Oncology Group Study. J. Urol. 2000, 163, 1124-1129. [CrossRef]

18. Humphrey, P.A.; Moch, H.; Cubilla, A.L.; Ulbright, T.M.; Reuter, V.E. The 2016 WHO Classification of Tumours of the Urinary System and Male Genital Organs-Part B: Prostate and Bladder Tumours. Eur. Urol. 2016, 70, 106-119. [CrossRef]

19. American Joint Committee on Cancer (AJCC) Staging Manual, 8th ed; Available online: www.cancerstaging.org (accessed on 15 August 2021).

20. Alvarez-Maestro, M.; Chierigo, F.; Mantica, G.; Quesada-Olarte, J.M.; Carrion, D.M.; Gomez-Rivas, J.; Pinto-Marin, A.; Bazan, A.A.; Martinez-Piñeiro, L. The effect of neoadjuvant chemotherapy among patients undergoing radical cystectomy for variant histology bladder cancer: A systematic review. Arab. J. Urol. 2021, 1-13. [CrossRef]

21. Sánchez-Rodríguez, C.; Cruces, K.P.; Ayora, J.R.; Martín-Sanz, E.; Sanz-Fernandez, R. BCG immune activation reduces growth and angiogenesis in an in vitro model of head and neck squamous cell carcinoma. Vaccine 2017, 35, 6395-6403. [CrossRef]

22. Medina, J.E. The Controversial Role of BCG in the Treatment of Squamous Cell Carcinoma of the Head and Neck. Arch. Otolaryngol. 1983, 109, 543. [CrossRef]

23. Raez, L.E.; Fein, S.; Podack, E.R. Lung cancer immunotherapy. Clin. Med. Res. 2005, 3, 221-228. [CrossRef] [PubMed] 
24. Podarala, V.; Lakshmi, M.P.; Venkata, S.K.R.; Devalam, R.P. Efficacy of BCG vaccine and Mitomycin C for the treatment of ocular squamous cell carcinoma in bovines. Res. Veter. Sci. 2020, 133, 48-52. [CrossRef] [PubMed]

25. Shokeir, A. Squamous cell carcinoma of the bladder: Pathology, diagnosis and treatment. BJU Int. 2004, 93, 216-220. [CrossRef] [PubMed] 